\title{
DGAT2 revealed by the immunogold technique in Arabidopsis thaliana lipid bodies associated with microtubules
}

\author{
Maria Kwiatkowska, Dariusz Stępiński, Katarzyna Popłońska, \\ Agnieszka Wojtczak, Justyna T. Polit
}

Department of Cytophysiology, University of Lodz, Poland

\begin{abstract}
The immunogold technique with anti-diacylglycerol acyltransferase 2 (DGAT2) antibody revealed in A. thaliana embryo and root meristematic cells gold particles manifesting the presence of DGAT2 in ER as well as in lipid bodies. This being so, lipid synthesis could take place both in ER and in the lipid bodies. The presence of microtubules around the lipid bodies was evidenced under transmission EM. Detection of tubulin around the lipid bodies using the immunogold technique with anti- $\alpha$-tubulin is in agreement with the above observations. Connection of lipid bodies with microtubules was also detected by us in other plants where they probably participated in lipid synthesis. A similar phenomenon may take place in A. thaliana. (Folia Histochemica et Cytobiologica 2012, Vol. 50, No. 3, 427-431)
\end{abstract}

Key words: DGAT2, lipid bodies, lipid synthesis, microtubules, ultrastructural immunogold technique

\section{Introduction}

Lipid bodies (lipid droplets, oleosomes) are the focus of interest for many scientists, as demonstrated by the large number of reviews concerning them [1-7]. They have become an important, and fascinating, object of research because they take part in many intracellular processes. The lipid bodies which are surrounded by a phospholipid monolayer are significantly different from other cell structures covered with a phospholipid bi-layer. This monolayer covers a triacylglycerol core.

Recent studies have suggested that the lipid bodies are not only lipid reservoirs, as previously thought, but are organelles which contain numerous proteins participating in signal transduction, regulation of synthesis, degradation and accumulation of lipids [1]. Disturbance of normal lipid homeostasis results in

Correspondence address: M. Kwiatkowska, Department of Cytophysiology, University of Lodz, Pomorska Str. 141/143, 90-236 Lodz, Poland; tel.: + 484263547 79, fax: + 484263545 14; e-mail: kwiat@biol.uni.lodz.pl numerous human diseases [8]. Understanding lipid body functions is also important because of plant productivity and biotechnology [9].

One problem concerning lipid bodies which needs explanation is the cellular site of lipid synthesis and accumulation. It is accepted that ER containing appropriate enzymes is such a site [10]. However, the presence of diacylglycerol acyltransferase 2 (DGAT2), an enzyme which, according to biochemical data [10] is able to transform diacylglycerol into triacylglycerol, indicates that lipid synthesis could still proceed in lipid bodies formed with contribution of ER [11]. An earlier paper also reached similar conclusions concerning palm [12]. Localization of this enzyme in plant cells with the immunogold technique has not been demonstrated to date. However, Shockey et al. [13], using the immunofluorescence technique, demonstrated that in tung tree DGAT1 and DGAT2 were located in distinct dynamic regions of ER. They concluded that these enzymes had non-redundant functions in the production of storage oils in plants.

The aim of the present study was to localise DGAT2 in $A$. thaliana cells. It has been demonstrated that there is a relationship between lipid bodies 
and microtubules in some species [14-19]; therefore, we wanted to check whether it referred also to A. thaliana.

\section{Material and methods}

Dry seeds of Arabidopsis thaliana, ecotype Columbia-0, were germinated for $24 \mathrm{~h}$ to obtain embryonic cells (seeds with mature embryo were imbibed for $24 \mathrm{~h}$ ), and for five days to obtain the root meristematic cells, in darkness at room temperature (RT).

Electron microscopy. The material was not incubated (embryo cells) or incubated (root cells) in $15 \mu \mathrm{M}$ taxol dissolved in the microtubule stabilizing buffer MSB (100 mM PIPES, $1 \mathrm{mM} \mathrm{MgCl} 2,5 \mathrm{mM}$ EGTA) $\mathrm{pH} 7.2$ at RT for $2 \mathrm{~h}$ then fixed in a mixture of $1 \% \mathrm{OsO}_{4}$ and $2.5 \%$ glutaraldehyde in $0.1 \mathrm{M}$ cacodylate buffer ( $\mathrm{pH} 7.2$ ) for $2 \mathrm{~h}$ and postfixed in $1 \% \mathrm{OsO}_{4}$ in the same buffer at $4^{\circ} \mathrm{C}$ for $3 \mathrm{~h}$.

After dehydration in the ethanol series, the material was embedded in a medium consisting of Epon 812 and Spurr's resin. Ultrathin sections ( $70 \mathrm{~nm}$ ) cut with a glass knife using a Reichert Jung Ultracut microtome were double stained with uranyl acetate and lead citrate according to Reynolds [20]. The sections were examined and photographed in a JEOL JEM 1010 transmission electron microscope at $80 \mathrm{kV}$ acceleration voltage.

Immunogold technique. The material was prepared as described in the EM section above. Freshly cut ultrathin sections were mounted on nickel formvar coated grids for EM investigations. Prior to immunogold reaction, the sections were treated with $10 \%$ hydrogen peroxide for $15 \mathrm{~min}$ to remove osmium which changes the antigen structure [21] and washed in distilled water and PBS (0.01 M, pH 7.4, Sigma). Air dried grids with the sections were blocked with $0.5 \%$ BSA and $0.05 \%$ Tween 20 in PBS for $20 \mathrm{~min}$ and then dried with tissue paper and incubated overnight at $20^{\circ} \mathrm{C}$ with the primary: 1) rabbit polyclonal anti-DGAT2 (H-70) antibody (Santa Cruz Biotechnology, USA) diluted in an antibody diluent (pH 8.0, no. S 0809, DAKO) at a 1:100 dilution; and 2) anti- $\alpha$-tubulin mouse monoclonal antibody (T-5168, Sigma) diluted in an antibody diluent ( $\mathrm{pH}$ 8.0, DAKO) at a 1:300 dilution. Then the grids were washed ten times for 5 min each in PBS and incubated with the secondary antibody 1) anti-rabbit IgG and 2) anti-mouse IgG both conjugated with $10 \mathrm{~nm}$ gold (Polysciences) diluted 1:40 in the antibody diluent (DAKO) for $1.5 \mathrm{~h}$ at the same temperature and rinsed again in PBS and distilled water (ten times for $5 \mathrm{~min}$ each). Ultrathin sections were double stained, examined and photographed as above. Sections not treated with the primary antibodies were the negative control.

Western blot analysis. Proteins from the root meristems of 5-day-old Arabidopsis thaliana seedlings were extracted us- ing a P-PER Plant Protein Extraction Kit (Pierce) according to the protocol, and then fractionated on $4-12 \%$ Bis Tris/MES PAGE-SDS gels (Novex) and blotted onto PVDF Membrane $0.2 \mu \mathrm{m}$ pore size (Invitrogen). Arabidopsis DGAT2 was detected with the rabbit polyclonal anti-DGAT2 (H-70) antibody raised against human enzyme (Santa Cruz Biotechnology, USA) diluted 1:500 using a Chromogenic Western Blot Immunodetection Kit (Invitrogen).

\section{Results and discussion}

Arabidopsis thaliana is a model species widely used e.g. to investigate the ultrastructure of lipid bodies [22]. These authors have demonstrated that lipid body sizes are determined by the amount of oleosins present on their surfaces.

In $A$. thaliana, DGAT has been identified and sequenced in a developing embryo and flower petals [23]. In the AS11mutant with disturbed composition of fatty acids, DGAT showed lowered activity which was correlated with reduced amount of triacylglycerides in $A$. thaliana seeds [24]. Moreover, it was shown that $A$. thaliana DGAT1 null mutant presented a reduced seed oil content of only $20-40 \%$, because another enzyme - phospholipid:diacylglycerol acyltransferase (PDAT1) supplemented fat synthesis. Double mutation of either enzyme decreases fat content by up to $80 \%$, resulting in disruption of embryo development [25].

To the best of our knowledge, DGAT localization in A. thaliana cells has not previously been studied. A cross-reaction using rabbit polyclonal antibody raised against human origin DGAT2 revealed one clear band at the molecular weight of about $44 \mathrm{kDa}$, which is consistent with the molecular mass of DGAT2 (Figure 1F). This result indicates that this antibody is specific and could be applied for the immunogold technique in our plant material, A. thaliana, as plant DGAT2 possesses high homology to DGAT2 of fungi and animals [26].

Images obtained using the immunogold technique demonstrated that gold particles, testifying to the presence of DGAT, were mainly localized near the monolayer or inside cytoplasmic lipid bodies (Figures 1A-C); the latter ones may be gold particles adhering to the monolayer tangential section (see Figure 1C). The gold particles occurred in plastids (Figure 1D) and in ER (Figure 1E). Microphotographs of sections without primary antibodies (negative control) were free of immunolabeling (not presented). Thus, localization of DGAT with the use of the immunogold technique in A. thaliana was similar to that in COS7 fibroblasts [11] and in O. umbellatum (Kwiatkowska et al. in prep.).

Microtubules have different diameters and can be stable or labile, with the result that their identifica- 


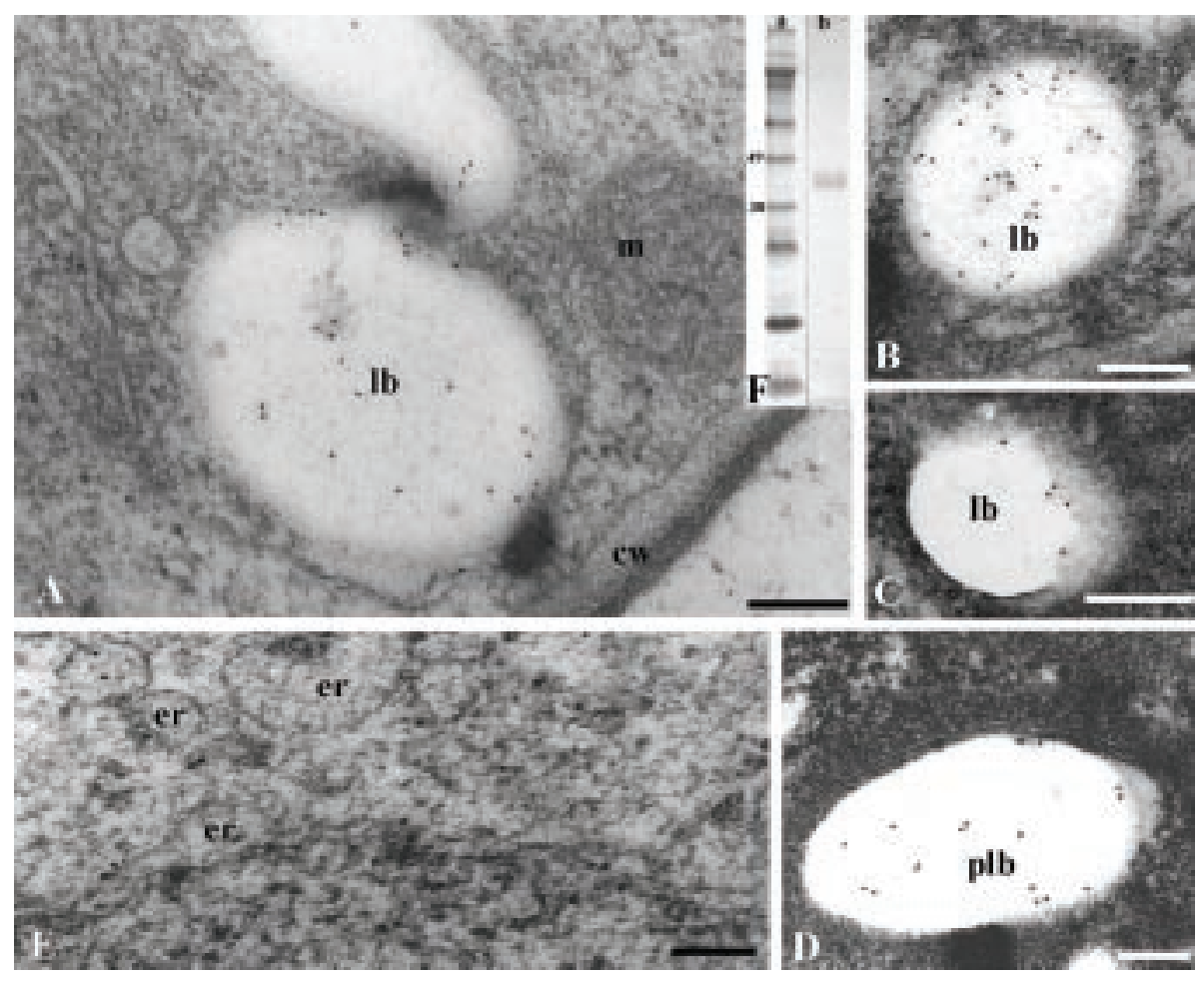

Figure 1. Detection of DGAT2 with the immunogold technique in A. thaliana embryo cells (A-E); gold particles around and inside cytoplasmic (A-C) and plastidic (D) lipid bodies as well as in endoplasmic reticulum (E); Immunoblotting analysis of DGAT2 in lysates of $A$. thaliana root meristematic cells $(\mathbf{F})$, lane a molecular weight marker, lane $\mathbf{b}$ Western blot of separated and electrotransferred proteins performed using primary rabbit anti-DGAT2 IgG fraction and secondary goat anti-rabbit IgG antibody conjugated with alkaline phosphatase

er — endoplasmic reticulum; lb - lipid body; $\mathrm{m}$ - mitochondrion; plb — plastidic lipid body; cw — cell wall; bar $200 \mathrm{~nm}$

tion around lipid bodies may be difficult. They need a special fixation procedure and high EM magnification. The lipid bodies of embryo cells non-incubated with taxol were connected with weakly visible microtubules (Figure 2A). That is why the cells incubated with taxol, which stabilizes microtubules and makes them more contrasted [17], were used in other preparations in the case of root meristems. Under high magnification, there were cross-sections of microtubules adjacent to a phospholipid monolayer around the lipid bodies with dark content (Figures 2B, F). Longitudinal section of microtubules can be seen in Figure 1E. Localization of $\alpha$-tubulin gold particles (around the white lipid bodies after $\mathrm{H}_{2} \mathrm{O}_{2}$ treatment) in root meristematic cells $24 \mathrm{~h}$ after germination (Figures $2 \mathrm{C}, \mathrm{D}$ ) was similar to that of cross-section microtubules (Figures 2A, B).

The presence of microtubules next to lipid bodies in some plants seems to indicate their functional correlation. Microtubules of $O$. umbellatum lipotubuloids (structures containing numerous lipid bodies connected with microtubules among which there are many ribosomes as well as ER vesicles and cisternae, a few mitochondria, Golgi structures and microbodies [14]) differ from the others identified so far close to the lipid bodies because they are covered with a polysaccharide layer [18]. Probably because of that, microtubules are very stable which is why they are a good model to investigate functional correlation between microtubules and lipid bodies. Autoradiographic studies in a light microscope with the use of ${ }^{3} \mathrm{H}$-palmitic acid have shown that the lipotubuloids of $O$. umbellatum were the site of intensive incorporation of this lipid precursor [27]. On the other hand, EM autoradiography revealed that silver particles were localized at the periphery of the lipid bodies where microtubules were touching them; all this led to the hypothesis that the surfaces of lipid bodies took part in lipid synthesis and that the microtubules co-operated with the lipid bodies in this process [15]. This hypothesis was proved by further research using the immunogold techinique. In O. umbellatum lipotubuloids (Kwiatkowska et al. in prep.) and in A. thaliana (the current work) as well as in COS7 fibroblasts [11], it has been shown that diacylglycerol acyltransferase 2 (DGAT2), an enzyme involved in the final stage of triacylglycerol synthesis, was present at the surfaces of lipid bodies, which may confirm the suggestion that lipid synthesis also occurs on them. 

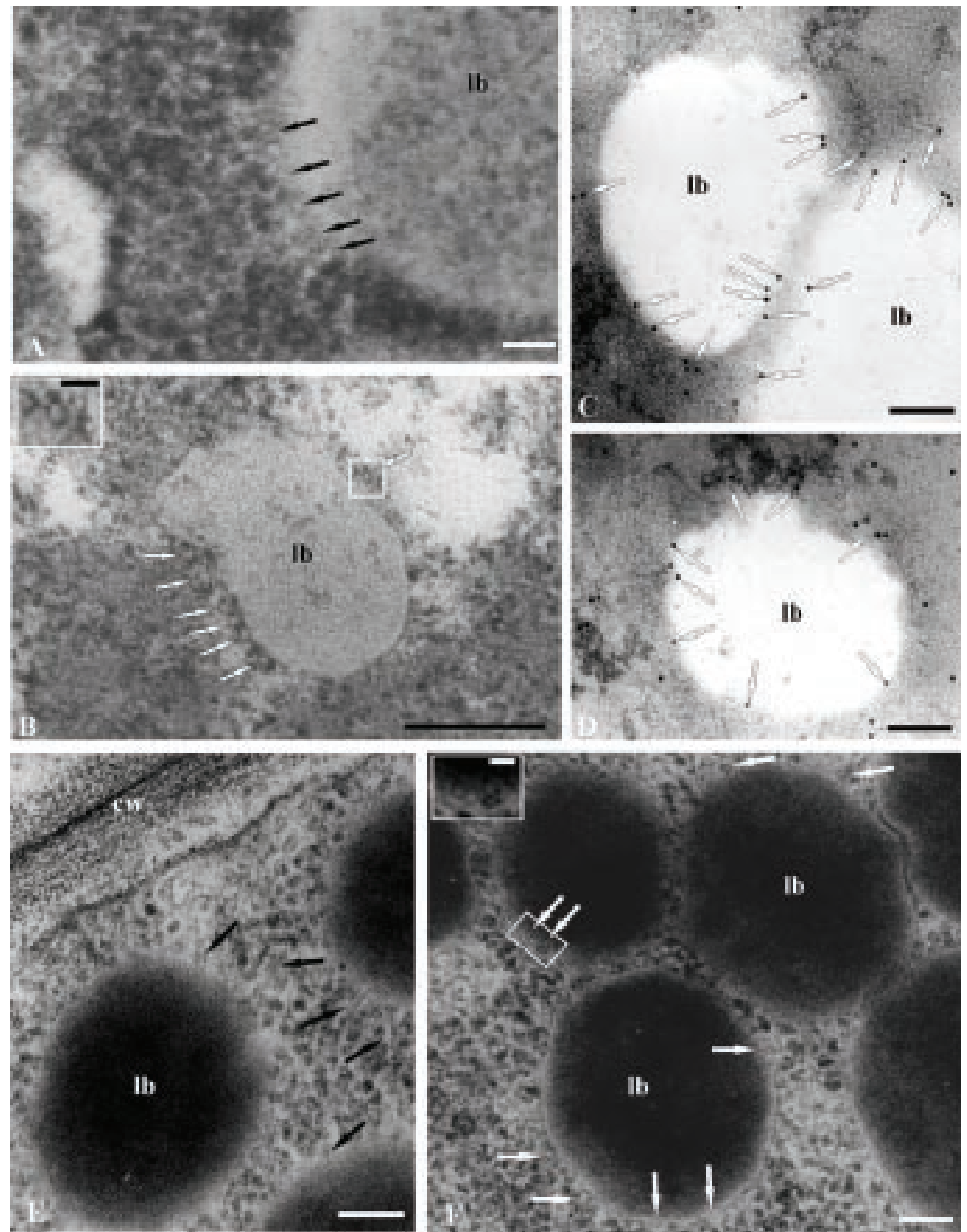

Figure 2. Lipid bodies of $A$. thaliana embryo cells non-incubated with taxol (A) and root meristematic cells treated with taxol (B-F). Immunogold detection of $\alpha$-tubulin; arrows show gold particles indicating tubulin presence around lipid bodies (C-D); black arrows indicate longitudinal sections of microtubules (E), white arrows indicate cross-sections of microtubules $(\mathbf{F})$

lb - lipid body; cw — cell wall; bars: $50 \mathrm{~nm}(\mathbf{A}), 100 \mathrm{~nm},(\mathbf{B}-\mathbf{F})$, inset bar: $12.5 \mathrm{~nm}(\mathbf{B}), 25 \mathrm{~nm}(\mathbf{F})$

Microtubules and lipid bodies in close contact have been observed in different animal cells in connection with lipid bodies' motion [28-30]. On the other hand, the observations of Pacheco et al. [19] implicate microtubule contribution to lipid synthesis. These authors observed that in mouse monocytes, toxins such as colchicine and taxol blocked lipid synthesis which was triggered by inflammatory factors. Our research also showed that the microtubule toxin, propyzamide, stopped the incorporation of the lipid precursor into $O$. umbellatum lipotubuloids which means lipid synthesis blockade (Kwiatkowska et al. in prep.) and confirms the view result- ing from autoradiographic and immunogold observations about the participation of microtubules in lipid synthesis.

In conclusion, on the basis of autoradiographic, ultrastructural observations with the use of ${ }^{3} \mathrm{H}$-palmitic acid and of immunocytochemical studies, showing localization of DGAT2 and phospholipase D near microtubules and in lipid bodies, the presumption has been made that in $O$. umbellatum lipid synthesis takes place in the lipid bodies but the microtubules play the role of transmitters carrying enzymes and lipid precursors indispensable for lipid synthesis (Kwiatkowska et al. in prep.). 
Although the microtubules entwining the lipid bodies in $A$. thaliana are less spectacular than in O. umbellatum, it seems probable that in this plant also the microtubules play a similar function i.e. participate in lipid synthesis as indicated by the presence of DGAT2.

\section{Acknowledgments}

This study was supported by the National Committee of Scientific Research, grant no. N N303 359035.

\section{References}

1. Beller M, Thiel K, Thul PJ, Jackle H. Lipid droplets: A dynamic organelle moves into focus. FEBS Lett. 2010;584:2176-2182 .

2. Digel M, Ehehalt R, Fullekrug J. Lipid droplets lighting up: Insights from live microscopy. FEBS Lett. 2010;584:2168-2175 .

3. Guo Y, Cordes KR, Farese Jr RV, Walther TC. Lipid droplets at a glance. J Cell Sci. 2009;122:749-752.

4. Ohsaki Y, Cheng J, Suzuki M, Shinohara Y, Fujita A, Fujimoto T. Biogenesis of cytoplasmic lipid droplets: From the lipid ester globule in the membrane to the visible structure. Biochem Biophys Acta. 2009;1791:399-407.

5. Olofsson S-O, Bostrom P, Andersson L, Rutberg M, Perman J, Boren J. Lipid droplets as dynamic organelles connecting storage and efflux of lipids. Biochem Biophys Acta. 2009;1791:448-458 .

6. Walther TC, Farese Jr RV. The life of lipid droplets. Biochem Biophys Acta. 2009;1791:459-466.

7. Zanghellini J, Wodlei HH, von Grunberg HH. Phospholipid demixing and the birth of a lipid droplet. $J$ Theor Biol. 2010;264:952-961.

8. Bozza PT, Magalhaes KG, Weller PF. Leukocyte lipid bodies - Biogenesis and functions in inflammation. Biochim Biophys Acta. 2009;1791:540-551.

9. Baud S, Lepiniec L. Physiological and developmental regulation of seed oil production. Prog Lipid Res. 2010;49:235-249 .

10. Lung S-Ch, Weselake RJ. Diacylglycerol acyltransferase: a key mediator of plant triacylglycerol synthesis. Lipids. 2006;41:1073-1088

11. Kuerschner L, Moessinger C, Thiele C. Imaging of lipid biosynthesis: How a neutral lipid enters lipid droplets. Traffic. 2008;9:338-352.

12. Oo Z-C, Chew Y-H. Diacylglycerol acyltransferase in microsomes and oil bodies of oil palm mesocarp. Plant Cell Physiol. 1992;33:189-195.

13. Shockey JM, Gidda SK, Chapital DC at al. Tung tree DGAT1 and DGAT2 have nonredundant functions in triacylglycerol biosynthesis and are localized to different subdomains of endoplasmic reticulum. Plant Cell. 2006;18:2294-2313.

14. Kwiatkowska M. Changes in the diameter of microtubules connected with the autonomous rotary motion of the lipotubuloids (elaioplast). Protoplasma. 1972a;75:345-357.
15. Kwiatkowska M. The incorporation of ${ }^{3} \mathrm{H}$-palmitic acid into Ornithogalum umbellatum lipotubuloids, which are a cytoplasmic domain rich in lipid bodies and microtubules. Light and EM autoradiography. Acta Soc Bot Pol. 2004;73:181-186.

16. Kwiatkowska M, Popłońska K, Kaźmierczak A, Stępiński D, Rogala K, Polewczyk K. Role of DNA endoreduplication, lipotubuloids, and gibberellic acid in epidermal cell growth during fruit development of Ornithogalum umbellatum.J Exp Bot. 2007;58:2023-2031.

17. Kwiatkowska M, Stępiński D, Popłońska K, Wojtczak A, Polit J. „Elaioplasts" of Haemanthus albiflos are true lipotubuloids: cytoplasmic domains rich in lipid bodies entwined by microtubules. Acta Physiol Plant. 2010;32:1189-1196.

18. Kwiatkowska M, Stępiński D, Polit J T, Popłońska K, Wojtczak A. Microtubule heterogeneity of Ornithogalum umbellatum ovary epidermal cells: non-stable cortical microtubules and stable lipotubuloid microtubules. Folia Histochem Cytobiol. 2011;49:285-290.

19. Pacheco P, Vieira-de-Abreu A, Gomes RN et al. Monocyte chemoattractant protein-1/CC chemokine ligand 2 controls microtubule-driven biogenesis and leukotriene $\mathrm{B}_{4}$-synthesizing function of macrophage lipid bodies elicited by innate immune response. J Immunol. 2007;179:8500-8508.

20. Reynolds ES. The use of lead citrate of high $\mathrm{pH}$ as an electron-opaque stain in electron microscopy. J Cell Biol. 1963; 17:208-212.

21. Bendayan M, Zollinger M. Ultrastructural localization of antigenic sites on osmium-fixed tissues applying the protein A-gold technique. J Histochem Cytochem. 1983;31:101-109.

22. Siloto RMP, Findlay K, Lopez-Villalobos A, Yeung EC, Nykiforuk CL. The accumulation of oleosins determines the size of seed oilbodies in Arabidopsis. Plant Cell. 2006;18:1961-1974 .

23. Hobbs DH, Lu C, Hills MJ. Cloning and cDNA encoding diacylglycerol acyltransferase from Arabidopsis thaliana and its functional expression. FEBS Lett. 1999;452:145-149.

24. Zou J, Wei Y, Jako C, Kumar A, Selvaraj G, Taylor DC. The Arabidopsis thaliana TAG1 mutant has a mutation in a diacylglycerol acyltransferase gene. Plant J. 1999;19:645-653.

25. Zhang M, Fan J, Taylor DC, Ohlrogge JB. DGATl and PDAT1 acyltransferases have overlapping functions in Arabidopsis triacylglycerol biosynthesis and are essential for normal pollen and seed development. Plant Cell. 2009;21:3885-3901.

26. Kroon JTM, Wei W, Simon WJ, Slabas AR. Identification and functional expression of a type 2 acyl-CoA: diacylglycerol acyltransferase (DGAT2 in developing castor bean seeds which has high homology to the major triglyceride biosynthetic enzyme of fungi and animals. Phytochem. 2006;67:2541-2549.

27. Kwiatkowska M. Autoradiographic studies on incorporation of $\left[{ }^{3} \mathrm{H}\right]$ palmitic acid into lipotubuloids of Ornithogalum umbellatum L. Folia Histochem Cytochem. 1972b;10:121-124.

28. Welte MA, Cermelli S, Griner J et al. Regulation of lipiddroplet transport by the perilipin homolog LSD2. Curr Biol. 2005;15:1266-1275.

29. Shubeita GT, Tran SL, Xu J at al. Consequences of motor copy number on the intracellular transport of kinesin-1 driven lipid droplets. Cell. 2008;135:1098-1107.

30. Spandl J, White DJ, Peychl J, Thiele C. Live cell multicolor imaging of lipid droplets with a new dye, LD540. Traffic. 2009;10:1579-1584. 